\title{
EFEITO DA ADIÇÃO DE LAMA VERMELHA NAS PROPRIEDADES ELETROQUÍMICAS E DE ADSORÇÃO DE UM LATOSSOLO VERMELHO
}

\author{
Mirian Chieko SHINZATO \\ Vanessa da Silva ANDRADE \\ José Vinícius MARTINS \\ Marília Mayumi Augusto dos SANTOS \\ Vinícius Tadeu RIBEIRO \\ Flávio Machado de Souza CARVALHO
}

\begin{abstract}
RESUMO
Esse estudo teve como objetivo caracterizar o resíduo gerado na produção de alumina a partir do refino de bauxita (lama vermelha) e analisar o seu efeito nas propriedades eletroquímicas e de adsorção de um solo tropical (Latossolo Vermelho). A lama vermelha (LM) é um resíduo extremamente alcalino ( $\mathrm{pH}$ em torno de 12) e rico em óxido/hidróxidos de ferro. Para estudar o efeito da lama vermelha e do carbonato de cálcio $\left(\mathrm{CaCO}_{3}\right)$ - comumente utilizado como corretivo de $\mathrm{pH}$ - no solo, essas substâncias foram adicionadas em diferentes proporções em amostras de Latossolo Vermelho por 60 dias. Verificou-se que a adição de $\mathrm{LM}$ e de $\mathrm{CaCO}_{3}$ no solo elevaram o $\mathrm{pH}$ e o ponto de carga zero (PCZ) do meio. No entanto, o valor de $\mathrm{pH}_{\mathrm{H} 2 \mathrm{O}}$ do solo com LM superou ao do respectivo PCZ, possibilitando a ocorrência de dispersão das partículas do solo. Por outro lado, essa adição favoreceu a capacidade de troca catiônica do solo, como pôde ser observado nos testes de remoção de $\mathrm{Pb}^{2+}$ em solução. Verificou-se que a adição mínima de $0,5 \%$ de $\mathrm{CaCO}_{3}$ e de $10 \%$ de $\mathrm{LM}$ no solo aumenta a capacidade de retenção de $\mathrm{Pb}^{2+}$ de $37 \%$ para $100 \%$. Essa mesma eficiência foi observada nos testes realizados somente com LM. Mesmo quando submetido a uma lixiviação ácida (solução pH 4,9) os solos incubados com $1 \%$ de $\mathrm{CaCO}_{3}$ e $1 \%$ de $\mathrm{LM}$ liberaram, respectivamente, 7,5\% e $11 \%$ de $\mathrm{Pb}^{2+}$ adsorvido. Essa pequena taxa de lixiviação de $\mathrm{Pb}^{2+}$ se deve ao aumento do $\mathrm{pH}$ do meio, que favorece a adsorção de $\mathrm{Pb}^{2+}$ pelos oxi-hidróxidos de $\mathrm{Al}$ e Fe presentes no solo e na lama vermelha. Conclui-se, portanto, que a adição da lama vermelha pode alterar as condições eletroquímicas do solo, tornando as partículas argilosas e coloidais mais dispersas. No entanto, por elevar o $\mathrm{pH}$ do sistema e apresentar óxidos e hidróxidos de $\mathrm{Fe}$ e $\mathrm{Al}$, esse material pode aumentar a retenção de metais pesados, como o $\mathrm{Pb}^{2+}$, no solo.
\end{abstract}

Palavras-chave: lama vermelha, Latossolo Vermelho, $\mathrm{pH}$, adsorção de $\mathrm{Pb}^{2+}$.

\section{ABSTRACT}

EFFECT OF THE ADDITION OF RED MUD ON THE ELECTROCHEMICAL AND ADSORPTION PROPERTIES OF AN OXISOL. This study aimed to characterize the waste generated in the production of alumina from bauxite refining process (red mud) and to analyze its effect on the electrochemical and adsorption properties of a tropical soil (Oxisol). The red mud (LM) is a highly alkaline residue ( $\mathrm{pH}$ around 12), which is rich in iron oxide/hydroxides. To study the effect of red mud and calcium carbonate $\left(\mathrm{CaCO}_{3}\right)$ - commonly used in agriculture to correct soil $\mathrm{pH}-$ on the soil, these substances were added in different proportions to Oxisol samples for 60 days. The addition of $\mathrm{CaCO}_{3}$ and $\mathrm{LM}$ to the soil increased the $\mathrm{pH}$ and the point of zero charge (PZC). However, the $\mathrm{pH}_{\mathrm{H} 2 \mathrm{O}}$ value of the soil with $\mathrm{LM}$ was greater than its PCZ, enabling dispersion of soil particles. Moreover, such addition increases cation exchange 
capacity in soils, as observed in removal tests of $\mathrm{Pb}^{2+}$ in solution. It was observed that the minimal addition of $0.5 \%$ of $\mathrm{CaCO}_{3}$ and $10 \%$ of $\mathrm{LM}$ to the soil increased the $\mathrm{Pb}^{2+}$ retention capacity from $37 \%$ to $100 \%$. The same results were observed in tests performed only with red mud. Even when subjected to an acid leaching (solution with $\mathrm{pH} 4.9$ ), soils incubated with $1 \% \mathrm{CaCO}_{3}$ and $1 \% \mathrm{LM}$ released $7.5 \%$ and $11 \%$ of retained $\mathrm{Pb}^{2+}$, respectively. This low $\mathrm{Pb}^{2+}$ leaching rate is due to the increase in soil $\mathrm{pH}$, favoring the adsorption of $\mathrm{Pb}^{2+}$ by $\mathrm{Fe}$ and $\mathrm{Al}$ oxy-hydroxides present in the soil and red mud composition. It can be concluded, therefore, that the addition of red mud can change the electrochemical conditions of the soil, dispersing more clay and colloidal particles. However, by increasing the $\mathrm{pH}$ of the system and introducing iron and aluminum oxides and hydroxides, such material can increase the retention of heavy metals, such as $\mathrm{Pb}^{2+}$, in the soil.

Keywords: red mud, Oxisol, pH, lead adsorption.

\section{INTRODUÇÃO}

A produção de alumínio inicia-se com a transformação da bauxita em alumina pela indústria primária a partir do Processo Bayer, onde é gerado um resíduo conhecido como lama vermelha que, além de ser extremamente alcalino $(\mathrm{pH}$ em torno de 12), é rico em óxido/hidróxidos de ferro os quais lhe dão a coloração avermelhada. Em seguida, por meio de eletrólise e na presença de criolita $\left(\mathrm{Na}_{3} \mathrm{AlF}_{6}\right)$ a alumina $\left(\mathrm{Al}_{2} \mathrm{O}_{3}\right)$, é reduzida a alumínio metálico (Processo Hall-Heróult).

Os números da produção do alumínio estão intimamente ligados à qualidade da bauxita. Em geral, cerca de 4 a $7 \mathrm{t}$ desse minério são necessárias para se produzir $2 \mathrm{t}$ de alumina, de onde se extrai $1 \mathrm{t}$ de alumínio (HYDRO 2015). Nesse processo produtivo cada tonelada de alumina gera 0,3 a 2,5 t de lama vermelha, dependendo da qualidade do minério (WORLD ALUMINUM ORG 2013). Devido a esse elevado volume, a lama vermelha comumente é disposta em extensas áreas a céu aberto (bacias de rejeito). Nos períodos de chuva intensa, as bacias podem transbordar e o resíduo contaminar áreas adjacentes e, consequentemente, causar sérios acidentes ambientais, como o ocorrido em Ajka (Hungria) em 2010.

$\mathrm{O}$ fato desse rejeito apresentar restos de soda cáustica $(\mathrm{NaOH})$ adquirida no processo Bayer, mesmo após ter sido lavado, torna-o altamente corrosivo e reativo e, por isso, é classificado como perigoso de acordo com a norma NBR 10004/2001 da ABNT (2004).

A composição química da lama vermelha pode variar em função do tipo de bauxita e do processo Bayer utilizado na produção. Normalmente esse resíduo é constituído por óxidos de ferro e de titânio, sílica e parte do aluminato de sódio não dissolvido no Processo Bayer e, ainda, depen- dendo do minério, de elementos químicos como cálcio, magnésio, vanádio, zircônio, tório, urânio, lantânio e selênio (LAAN \& VLIET 1998, KARA \& EMRULLAHOGLU 2000). As condições alcalinas herdadas do Processo Bayer fornecem à lama vermelha uma significativa carga negativa sobre a sua superfície, a qual pode interferir substancialmente no processo de floculação (CHVEDOV et al. 2001).

Os principais componentes da lama vermelha são a hematita $\left(\alpha-\mathrm{Fe}_{2} \mathrm{O}_{3}\right)$, goethita $(\alpha-\mathrm{FeOOH})$, magnetita $\left(\mathrm{Fe}_{3} \mathrm{O}_{4}\right)$, boemita $(\gamma-\mathrm{AlOOH})$, quartzo $\left(\mathrm{SiO}_{2}\right)$, sodalita $\left(\mathrm{Na}_{4} \mathrm{Al}_{3} \mathrm{Si}_{3} \mathrm{O}_{12} \mathrm{Cl}\right)$ e gipsita $\left(\mathrm{CaSO}_{4} \cdot 2 \mathrm{H}_{2} \mathrm{O}\right)$, além de calcita $\left(\mathrm{CaCO}_{3}\right)$ e gibbsita $\left(\mathrm{Al}(\mathrm{OH})_{3}\right)$, em menor proporção (BRUNORI et al. 2005).

Diante do elevado volume de lama vermelha gerado pela indústria do alumínio, torna-se importante buscar alternativas para o reaproveitamento desse material. Vários estudos têm demonstrado, por exemplo, a viabilidade de se utilizar a lama vermelha como agente de remoção de metais pesados em efluentes industriais (HO \& QIAO 1998, LAAN \& VLIET 1998, GUPTA et al. 2001, COSTA et al. 2008), bem como no tratamento de drenagens ácidas de minerações (DOYE \& DUCHESNE 2003).

$\mathrm{Na}$ agricultura, a lama vermelha foi testada como uma alternativa para correção de pH em solos ácidos (SNARS et al. 2002, VARNAVAS et al. 2005) ou, ainda, como um aditivo para enriquecê-los com ferro (HIND et al. 1999). A aplicação desse resíduo no solo pode promover, ainda, o aumento da retenção de fósforo e a imobilização de metais pesados em áreas contaminadas, seja por adsorção e/ou co-precipitação de óxidos e hidróxidos durante as reações de neutralização (LOMBI et al. 2002, CICCU et al. 2003, BRUNORI et al. 2005, LI et al. 2010). 
Uma vez que a adição de lama vermelha num sistema em equilíbrio pode promover alterações nas cargas das partículas sólidas, o conhecimento das propriedades eletroquímicas dos solos, assim como do próprio resíduo, é imprescindível para o avanço dos estudos nessa área.

Nesse sentido, o presente artigo apresenta as características química e mineralógica de uma lama vermelha proveniente de uma indústria brasileira de refino da bauxita e seus efeitos nas propriedades eletroquímicas e de adsorção de metais pesados, ao ser adicionada num Latossolo Vermelho - um dos mais representativos tipos de solo tropical - por meio de trabalhos experimentais em laboratório.

\section{MATERIAIS E MÉTODOS}

Nesse estudo foram utilizadas amostras de Latossolo Vermelho do Município de Araraquara (SP), coletadas entre $0-20 \mathrm{~cm}$ de profundidade, de acordo com os procedimentos estabelecidos pelo Instituto Agronômico de Campinas (CAMARGO et al. 2009). Esse latossolo está associado à decomposição de rochas efusivas básicas, metabasitos e tufitos, que ocorrem em extensas áreas dos estados de São Paulo, Paraná, Santa Catarina, Rio Grande do Sul, Minas Gerais, Mato Grosso, Mato Grosso do Sul e Goiás (KER 1997).

A amostra de lama vermelha encontra-se na forma desidratada e é proveniente de uma indústria de refino de bauxita localizada em Ouro Preto (MG).

Precedendo os trabalhos experimentais, as amostras de solo e de lama vermelha foram secas em estufa à $50{ }^{\circ} \mathrm{C}$ por $24 \mathrm{~h}$ e homogeneizadas por quarteamento, antes de sua caracterização química e mineralógica.

2.1 Caracterização química, física e mineralógica dos materiais

A amostra de Latossolo Vermelho foi caracterizada no trabalho de WU et al. (2013), que utilizou os métodos de difração e de fluorescência de raios X para obter, respectivamente, a composição mineralógica e química desse solo.

A caracterização química da lama vermelha também foi executada por fluorescência de raios X (Panalytical, modelo Axios Advanced) no Laboratório de Caracterização Tecnológica da Escola Politécnica da Universidade de São Paulo (LCT/POLI/USP). A análise mineralógica foi realizada no Laboratório de Difração de raios X do Instituto de Geociências da USP com um equipamento da Siemens/D500, com radiação $\mathrm{CuK} \alpha$, varredura de 3 a $65^{\circ}$, passo de $0,050^{\circ}$ e tempo de contagem de $0,5 \mathrm{seg} /$ passo.

A granulometria da lama vermelha foi determinada por meio da técnica de espalhamento de luz laser de baixo ângulo em dispersante aquoso no equipamento Malven Mastersize do LCT/POLI/ USP. Esses dados são relevantes para os estudos de sorção, uma vez que as interações entre o sorvente (lama vermelha) e o sorbato (íon metálico) acontecem por interações superficiais que dependem da sua área superficial específica.

Uma vez que os solos e a lama vermelha são formados principalmente por compostos, cujas propriedades de adsorção dependem fortemente do $\mathrm{pH}$ do meio, determinou-se duas propriedades: a capacidade de troca catiônica (CTC) e o ponto de carga zero (PCZ).

A CTC consiste na maior ou menor capacidade do material em atrair cátions em sua superfície, partindo-se do princípio que os íons retidos na superfície de uma fase sólida serão substituídos pela mesma quantidade de outros íons de mesma espécie em uma fase líquida. A CTC foi analisada de acordo com o método proposto por HESSE (1971), onde a amostra é saturada primeiramente com solução de acetato de sódio $\left(1 \mathrm{~mol} \mathrm{~L}^{-1}\right)$ a pH 7 e, em seguida, com acetato de amônio (1 mol $\mathrm{L}^{-1}$ ) a $\mathrm{pH}$ 7. A concentração de sódio deslocado pelo amônio foi determinada no espectrofotômetro de chamas (DM-62/Digimed).

$\mathrm{O}$ ponto de carga zero (PCZ), por sua vez, representa o $\mathrm{pH}$ quando a soma das quantidades de cargas superficiais positivas e negativas das partículas do material é nula. O PCZ mostra a maior ou menor tendência em adsorver cátions ou ânions, conforme o pH da solução em que o material está inserido. Caso o $\mathrm{pH}$ do meio esteja abaixo do PCZ do material, haverá predomínio de cargas positivas na sua superfície, que proporcionará, então, a adsorção aniônica. Por outro lado, se o pH estiver acima do PCZ, o material dará preferência à troca catiônica, por predominar cargas negativas na superfície do adsorvente (ALLEONI et al. 2009). No presente experimento, essa propriedade foi determinada seguindo-se o método proposto por CAMARGO et al. (2009); todas as leituras de $\mathrm{pH}$ foram realizadas no equipamento HI 8424 da Hanna Instruments.

A alcalinidade da lama vermelha, ou seja, os parâmetros correspondentes ao conteúdo de carbonato $\left(\mathrm{CO}_{3}^{2-}\right)$, bicarbonato $\left(\mathrm{HCO}^{3-}\right)$ e hidroxilas $\left(\mathrm{OH}^{-}\right)$(ARANA 2004) presentes no material (expressa em $\mathrm{mg}$ de $\mathrm{CaCO}_{3} \mathrm{~L}^{-1}$ ), foram determinados segundo o método proposto por HYPOLITO et al. 
(2008), em soluções preparadas com três proporções distintas de lama vermelha e água destilada $(1: 75,1: 150$ e $1: 300)$.

\subsection{Testes experimentais}

Os trabalhos experimentais foram divididos em três etapas (Figura 1).

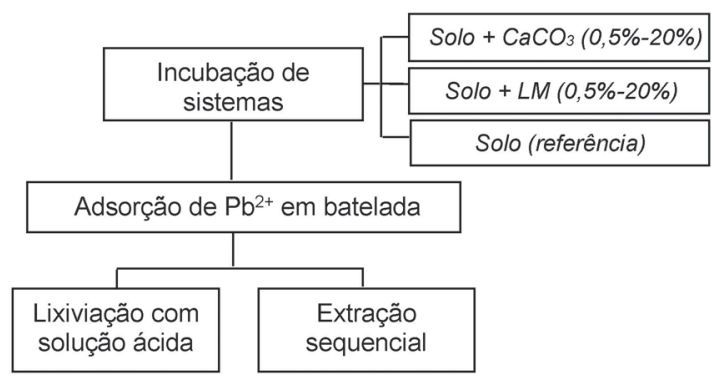

FIGURA 1 - Etapas de trabalhos experimentais.

A primeira etapa corresponde ao teste de incubação da lama vermelha no solo, que teve o objetivo de estudar o efeito desse material nas propriedades eletroquímicas do solo. Outra série de testes, fazendo uso do carbonato de cálcio $\left(\mathrm{CaCO}_{3}\right)$, comumente empregado na correção de $\mathrm{pH}$ de solos agrícolas, foi preparada para comparar com os dados da lama vermelha. Um terceiro teste contendo apenas solo também foi realizado para servir de referência.

A segunda etapa teve o objetivo de avaliar a capacidade dos constituintes do solo e da lama vermelha em reter metais pesados por meio de testes de batelada, utilizando soluções de chumbo $\left(\mathrm{Pb}^{2+}\right)$.

Por último, as amostras utilizadas na etapa anterior, ou seja, aquelas que adsorveram $\mathrm{Pb}^{2+}$, foram utilizadas nos testes de lixiviação ácida e de extração sequencial, para verificar a afinidade do chumbo pelos componentes do solo.

\subsubsection{Incubação do solo}

Montou-se duas séries de 6 recipientes plásticos com $100 \mathrm{~g}$ de solo em cada frasco. Na primeira juntou-se lama vermelha e na outra $\mathrm{CaCO}_{3}$ nas mesmas proporções de $0,5 \%, 1 \%, 3 \%, 5 \%, 10 \%$ e $20 \%$ em massa. A proporção de $0,5 \%$ corresponde ao valor da necessidade de calagem (NC) requerida por uma cultura que utiliza $2,5 \mathrm{t} \mathrm{ha}^{-1}$ de calcário, e também representa o $\mathrm{NC}$ de alguns latossolos paulistas (CAMPANHARO et al. 2007). As demais proporções simulam o uso excessivo de aditivos nos solos (seja em quantidade como em frequência), uma prática comum de muitos agricultores que desconhecem a dosagem correta.

As misturas de solo $+\mathrm{LM}$ e solo $+\mathrm{CaCO}_{3}$ foram mantidas incubadas por 60 dias, sob temperatura de $25{ }^{\circ} \mathrm{C}$ e umidade em torno de $70 \%$ da capacidade de campo. No final do período de incubação determinou-se o pH do solo em uma solução de $\mathrm{CaCl}_{2}\left(0,01 \mathrm{~mol} \mathrm{~L}^{-1}\right)$, segundo metodologia de RAIJI et al. (2011). Nesse teste também foram determinados os valores de $\mathrm{PCZ}$ e o $\mathrm{pH}$ em água e na solução de $\mathrm{KCl}\left(1 \mathrm{~mol} \mathrm{~L}^{-1}\right)$, a fim de se obter dados de $\Delta \mathrm{pH}$ (eq. 1), importante parâmetro associado às propriedades eletroquímicas do solo (MEKARU \& UEHARA 1972; BENITES \& MENDONÇA 1998). Para medir o $\mathrm{pH}$ em KCl $\left(1 \mathrm{~mol} \mathrm{~L}^{-1}\right)$ e em água destilada, utilizou-se a mesma metodologia para determinação do $\mathrm{pH}$ em solução de $\mathrm{CaCl}_{2}$ $\left(0,01 \mathrm{~mol} \mathrm{~L}^{-1}\right)$.

$$
\Delta \mathrm{pH}=\mathrm{pH}_{\mathrm{KCl}}-\mathrm{pH}_{\mathrm{H} 2 \mathrm{O}} \quad \text { (Equação 1) }
$$

Quando o $\mathrm{pH}$ em $\mathrm{KCl}\left(1 \mathrm{~mol} \mathrm{~L}^{-1}\right)$ for inferior ao $\mathrm{pH} \mathrm{em} \mathrm{H}_{2} \mathrm{O}$, existe um indicativo de que o $\mathrm{Cl}^{-}$deslocou menor quantidade de $\mathrm{OH}^{-}$em relação ao $\mathrm{H}^{+}$deslocado pelo $\mathrm{K}^{+}$. Nesse caso, a amostra é interpretada como eletronegativa, ou seja, a sua CTC é maior que a CTA; o oposto, mais comum no horizonte $\mathrm{B}$ de alguns Latossolos ácricos (MOTTA \& MELO 2009), indica o predomínio de cargas positivas.

Ainda de acordo com BENITES \& MENDONÇA (1998), além do $\Delta \mathrm{pH}$ ser um bom estimador do potencial elétrico superficial das partículas do solo, os valores de $\mathrm{pH}$ em $\mathrm{KCl}$ e em $\mathrm{H}_{2} \mathrm{O}$ também permitem determinar o Ponto de Efeito Salino Nulo (PESN), que corresponde ao Ponto de Carga Zero (PCZ) relacionado somente com as cargas variáveis. PRADO (2003) mostra que o PCZ também pode ser estimado indiretamente a partir da equação (2), originalmente proposta por UEHARA (1979).

$$
\mathrm{PCZ}=2 \mathrm{pH}_{\mathrm{KCl}}-\mathrm{pH}_{\mathrm{H} 2 \mathrm{O}} \quad \text { (Equação 2) }
$$

Segundo PRADO (2003), a dispersão da argila pode ser dada pela equação de Nernst (OLPHEN 1977), que é proporcional à diferença entre os valores de PCZ e o pH em água do solo. Esse parâmetro é denominado de afastamento (AFAS) e pode ser determinada pela equação 3 (RAIJ \& PEECH 1972).

$$
\mathrm{AFAS}=\mathrm{pH}_{\mathrm{H} 2 \mathrm{O}}-\mathrm{PCZ} \quad \text { (Equação 3) }
$$


A determinação do afastamento mostra-se importante, uma vez que permite verificar se pode haver dispersão de argila com a adição da lama vermelha no solo. FONTES et al. (1995) observaram que a dispersão da argila em solos pode ocorrer devido ao aumento da carga líquida negativa e da espessura da dupla camada elétrica difusa, em função da substituição do alumínio pelo cálcio e magnésio do calcário usado como corretivo de $\mathrm{pH}$. De forma geral, a dispersão da argila aumenta quando o $\mathrm{pH}$ em água do solo se torna mais elevado do que o $\mathrm{PCZ}$, devido à ocorrência de maior repulsão eletrostática e diminuição da floculação (RAIJ \& PEECH 1972).

Em vista disso, valores elevados de AFAS indicam um aumento da carga líquida negativa dos colóides do solo, tornando-o suscetível à erosão (PRADO 2003). Inúmeros experimentos encontrados na literatura sugerem que a redução da dispersão da argila diminui à medida que os valores de $\mathrm{PCZ}$ e de $\mathrm{pH}_{\mathrm{H} 2 \mathrm{O}}$ do solo também decrescem (ALBUQUERQUE et al. 2000).

2.2.2 Testes de batelada - retenção de $\mathrm{Pb}^{2+}$ em solução

Esses testes foram realizados para avaliar a capacidade do solo, da lama vermelha (LM) e dos solos incubados com lama vermelha e $\mathrm{CaCO}_{3} \mathrm{em}$ adsorver metais em solução. Utilizou-se solução com concentração de $100 \mathrm{mg} \mathrm{L}^{-1}$ de $\mathrm{Pb}^{2+}$, preparada a partir de sal de grau analítico de $\mathrm{Pb}\left(\mathrm{NO}_{3}\right)_{2}$ (Merck) e pH de 5. Juntou-se, então, $40 \mathrm{~mL}$ da solução com $100 \mathrm{mg} \mathrm{L}^{-1}$ de $\mathrm{Pb}^{2+}$ e $1 \mathrm{~g}$ de amos- tra, que foram agitadas por $24 \mathrm{~h}$ em agitador tipo Wagner. Em seguida, as soluções foram centrifugadas e filtradas para determinar a concentração de $\mathrm{Pb}^{2+}$ remanescente. Esses experimentos foram realizados em duplicata e os resultados consistem no valor da média obtida em cada teste.

\subsubsection{Lixiviação ácida e extração sequencial}

O efeito de uma chuva ácida num solo contaminado com $\mathrm{Pb}^{2+}$ foi simulado com amostras saturadas desse metal, as quais foram lixiviadas com uma solução de ácido acético de pH 4,9 (preparada de acordo com a NBR 10.005 da ABNT 2004). Nessa simulação, $1 \mathrm{~g}$ de cada amostra foi adicionado a $20 \mathrm{~mL}$ de ácido acético, que permaneceu em contato por $18 \mathrm{~h}$, e sob agitação; em seguida, mediu-se o teor de $\mathrm{Pb}^{2+}$ nas soluções filtradas.

O chumbo associado ao solo das amostras solo $+20 \% \mathrm{LM}$, solo $+20 \% \mathrm{CaCO}_{3}$ e à amostra de lama vermelha foi quantificado a partir da técnica de extração sequencial. A extração sequencial é muito conhecida e útil para se determinar as diferentes fases do solo em que os metais se associam quando adicionados ao meio, além de determinar a sua mobilidade. Essa técnica permite obter informações sobre ocorrência, biodisponibilidade, mobilização e transporte do metal no solo (SÁNCHEZ-MARTÍN et al. 2007).

A série iniciou-se com soluções mais fracas (menos destrutivas) até as mais agressivas e destrutivas. Os dados da metodologia adotada em cada etapa de extração encontram-se descritos na tabela 1 .

TABELA 1 - Condições das etapas de extração sequencial.

\begin{tabular}{|c|c|c|c|c|}
\hline Etapas & Fração & Reagente & solo:extrator & Temperatura \\
\hline 1 & Solúvel & $\mathrm{H}_{2} \mathrm{O}$ ultrapura & $2: 10$ & ambiente \\
\hline 2 & Trocável & $\mathrm{MgCl}_{2}(1 \mathrm{M})$ & $2: 20$ & ambiente \\
\hline 3 & Carbonatos & $\mathrm{CH}_{3} \mathrm{COONa}(1 \mathrm{M})$ & $2: 20$ & ambiente \\
\hline 4 & Matéria orgânica & $\mathrm{NaClO}(1 \mathrm{M})$ & $2: 6$ & $90^{\circ} \mathrm{C}$ \\
\hline 5 & Óxidos de $\mathrm{Fe}$ e $\mathrm{Al}$ amorfos & *Mistura de soluções & $2: 40$ & ambiente \\
\hline 6 & Óxidos de $\mathrm{Al}$ cristalinos & $\mathrm{NaOH}(1,25 \mathrm{M})$ & $2: 40$ & $75^{\circ} \mathrm{C}$ \\
\hline 7 & Residual & $3 \mathrm{HCl}: \mathrm{HNO}_{3}$ & $2: 10$ & $90^{\circ} \mathrm{C}$ \\
\hline
\end{tabular}

*Mistura de soluções de ácido oxálico $\left(0,2 \mathrm{~mol} \mathrm{~L}^{-1}\right)$, ácido ascórbico $\left(0,1 \mathrm{~mol} \mathrm{~L}^{-1}\right)$ e oxalato de amônio $\left(0,2 \mathrm{~mol} \mathrm{~L}^{-1}\right)$. 
O método de extração de todas as fases, com exceção da trocável e residual, baseou-se no trabalho de KUMMER et al. (2011), adaptado dos trabalhos de MANN \& RITCHIE (1993) e de GOMES et al. (1997). Para a extração das fases trocável e residual, foram utilizados, respectivamente, os métodos adaptados de TESSIER et al. (1979) e de USEPA (1996). Cada etapa de extração foi realizada agitando-se a mistura e, após a sua centrifugação, o sobrenadante foi coletado para análise do teor de $\mathrm{Pb}^{2+}$ liberado na solução.

2.2.4 Métodos analíticos e quantificação do chumbo

A concentração de $\mathrm{Pb}^{2+}$ das soluções obtidas nos testes de batelada foi determinada por dois métodos:

1. Espectrometria de emissão óptica com plasma indutivamente acoplado (ICP-OES) no equipamento ARL-3410 do Laboratório de Química e ICP-OES/MS do Instituto de Geociências da Universidade de São Paulo (IGc/USP);

2. Espectrometria de absorção atômica Varian Spectra AA 50 do Laboratório Didático de Química Analítica Instrumental do Instituto de Química da Universidade de São Paulo (IQ/USP).

Para o controle de qualidade dessas análises químicas, todas as soluções utilizadas nos testes experimentais e também para calibrar os equipamentos foram preparadas com sal de grau analítico de $\mathrm{PbNO}_{3}$.
A eficiência (\%) de retenção de $\mathrm{Pb}^{2+}$ pelos materiais analisados foi determinada pela equação (4). A quantidade de chumbo (mg) removida por grama de amostra de solo foi obtida utilizando-se a equação (5).

Eficiência $(\%)=\left[\frac{C_{i}-C_{x}}{C_{i}}\right] \times 100 \quad($ Equação 4)

$\operatorname{Remoção~}(m g / g)=\frac{\left[C_{i}-C_{x}\right]}{m} \times V \quad($ Equação 5)

onde, $C_{i}$ corresponde à concentração inicial $(\mathrm{mg}$ $\left.\mathrm{L}^{-1}\right)$ de $\mathrm{Pb}^{2+}$ na solução; $C_{x}$ é a concentração final $\left(\mathrm{mg} \mathrm{L}^{-1}\right)$ de $\mathrm{Pb}^{2+} ; V$ é o volume de solução com $\mathrm{Pb}^{2+}$ (L) e $m$, a massa de solo (g).

\section{RESULTADOS E DISCUSSÃO}

3.1 Caracterização mineralógica, química e física dos materiais

\subsubsection{Lama vermelha}

A análise do difratograma de raios $\mathrm{X}$ da lama vermelha (Figura 2) revelou que esse material é formado principalmente por minerais de hematita $\left(\mathrm{Fe}_{2} \mathrm{O}_{3}\right)$, quartzo $\left(\mathrm{SiO}_{2}\right)$, caulinita $\left(\mathrm{Al}_{2} \mathrm{Si}_{2} \mathrm{O}_{5}(\mathrm{OH})_{4}\right)$, e goethita $(\mathrm{FeO}(\mathrm{OH}))$. Esse difratograma apresenta também alguns pequenos picos referentes aos compostos com estruturas da bayerita $\left(\alpha-\mathrm{Al}(\mathrm{OH})_{3}\right)$ e da sodalita $\left(\mathrm{Na}_{4} \mathrm{Al}_{3} \mathrm{Si}_{3} \mathrm{O}_{12} \mathrm{Cl}\right)$.

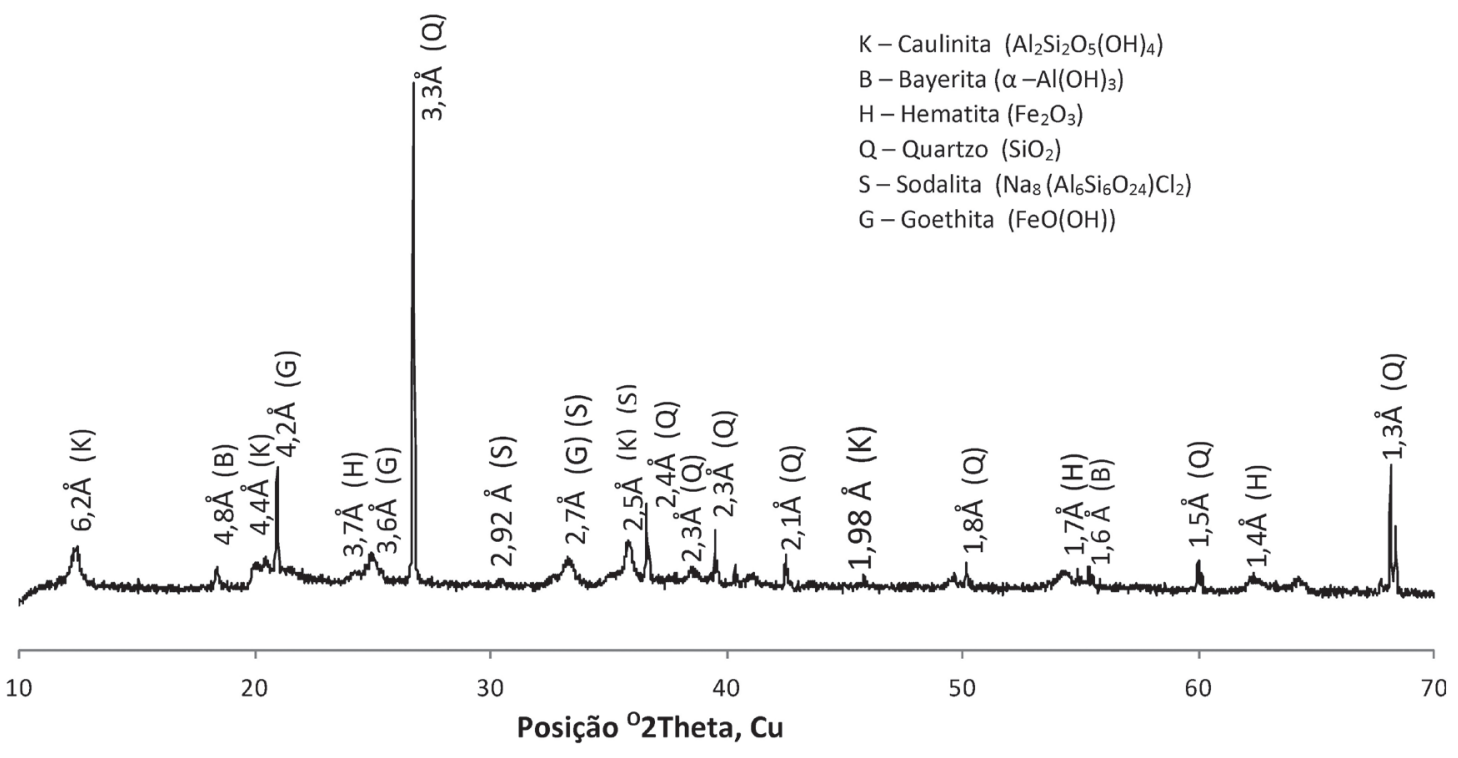

FIGURA 2 - Difratograma de raios X da lama vermelha (LM). 
A bayerita e a sodalita formam-se durante a digestão alcalina da bauxita. A sodalita, em particular, resulta da dissolução de minerais de silício, como a caulinita; esse processo é conhecido como dessilicação (CHVEDOV et al. 2001). Os demais minerais (hematita, goethita, caulinita e quartzo) são provenientes da bauxita. Cabe ressaltar que esses minerais e compostos caracterizam-se por adquirir carga variável no solo e, portanto, a sua propriedade de adsorção depende do $\mathrm{pH}$ do meio.

A presença de hematita $\left(\mathrm{Fe}_{2} \mathrm{O}_{3}\right)$ e goethita $(\alpha-\mathrm{FeOOH})$ é comum na composição das lamas vermelhas; os demais componentes podem diferir de acordo com o tipo de bauxita e processos utilizados na sua digestão. Por exemplo, a lama vermelha estudada por DUCHESNE \& DOYE (2005), proveniente da planta industrial de Vaudreuil (Canadá) da ALCAN (2005), possui ainda gibbsita $\left(\mathrm{Al}(\mathrm{OH})_{3}\right)$, boehmita $(\mathrm{AlOOH})$, sodalita $\left(\mathrm{Na}_{8}\left(\mathrm{Si}_{6} \mathrm{Al}_{6} \mathrm{O}_{24}\right) \mathrm{Cl}_{2}\right)$, anatásio $\left(\mathrm{TiO}_{2}\right)$, rutilo $\left(\mathrm{TiO}_{2}\right)$, katoita $\left(\mathrm{Ca}_{3} \mathrm{Al}_{2} \mathrm{SiO}_{4}(\mathrm{OH})_{12}\right)$ e traços de gipsita $\left(\mathrm{CaSO}_{4} 2 \mathrm{H}_{2} \mathrm{O}\right)$.

Quanto à composição química (Tabela 2), verificou-se que a lama vermelha é constituída principalmente pelos componentes dos minerais presentes originalmente na bauxita, como $\mathrm{Fe}_{2} \mathrm{O}_{3}$ da hematita e goethita e $\mathrm{SiO}_{2}$ e $\mathrm{Al}_{2} \mathrm{O}_{3}$ da caulinita. Parte da alumina também provém da bayerita formada durante a digestão alcalina.

Nessa composição, destacam-se também $\mathrm{Na}_{2} \mathrm{O}$ e $\mathrm{CaO}$, introduzidos durante o processo Bayer na forma de carbonato de cálcio e hidróxido de sódio, $\mathrm{TiO}_{2}$, presente originalmente na bauxita, além de componentes químicos de interesse econômico como Zr, Th, Ga, V e elementos terras raras Ce e $\mathrm{Y}$.

Apesar da composição da lama vermelha variar com o tipo de minério processado, alguns componentes são comuns e outros podem ser encontrados em maior ou menor teores, como os óxidos de ferro e de titânio, sílica e parte do aluminato de sódio não dissolvido no Processo Bayer. Além dos elementos encontrados na lama vermelha analisada no presente estudo, LAAN \& VLIET (1998) e
KARA \& EMRULLAHOGLU (2000) também detectaram a presença de magnésio, urânio, lantânio e selênio nos resíduos de bauxitas provenientes, respectivamente, de Serra Leoa e da Austrália.

Ressalta-se ainda que o material também possui em sua composição alguns metais pesados como $\mathrm{PbO}(0,02 \%)$ e $\mathrm{ZnO}(0,01 \%)$. No entanto, a presença desses metais não inviabiliza o seu uso como adsorvente, uma vez que essa propriedade depende das condições de $\mathrm{pH}$ e, nesse caso, não seriam disponibilizados para o meio. COSTA et al. (2009) também encontraram $\mathrm{Pb}^{2+}$ (cerca de $0,07 \%$ ) na lama vermelha de uma indústria localizada em Poços de Caldas (MG) e concordaram com o uso potencial desse material como adsorvente e amenizante de solos contaminados com elementos-traço.

$\mathrm{O}$ valor de perda ao fogo (PF) a $1050{ }^{\circ} \mathrm{C}$ da lama vermelha corresponde, por sua vez, à perda de compostos voláteis do material como a água, carbonatos e hidroxilas.

A interpretação da curva acumulativa e curva de frequência obtida na análise granulométrica de lama vermelha (Figura 3) mostra que $10 \%$ de suas partículas possuem tamanho menor que $0,812 \mu \mathrm{m}$, $50 \%$ são menores que $7,583 \mu \mathrm{m}$ e $90 \%$ são menores que $164,504 \mu \mathrm{m}$.

A análise desses dados permite verificar que a amostra é composta por $20 \%$ de argila, $60 \%$ de silte e $20 \%$ de areia, sendo classificada como de textura franco-siltosa, de acordo com o triângulo textural utilizado pelo Sistema Brasileiro de Classificação de Solos (LEMOS \& SANTOS 1984). A curva de frequência do material é bimodal e, portanto, trata-se de um material pouco selecionado.

A granulometria da lama vermelha pode variar conforme a origem da bauxita e do processo de beneficiamento utilizado, mas nesse estudo, predominam as frações areia e silte. Todavia, por comparação, a lama vermelha da indústria de refino de bauxita localizada em Alumínio (SP) possui 6,37\% de areia, $57,8 \%$ de silte e $35,8 \%$ de argila (ANTUNES et al. 2011).

TABELA 2 - Componentes químicos da lama vermelha. Teor em \% (massa).

\begin{tabular}{cccccccccccccc}
\hline $\mathrm{Na}_{2} \mathrm{O}$ & $\mathrm{Al}_{2} \mathrm{O}_{3}$ & $\mathrm{SiO}_{2}$ & $\mathrm{P}_{2} \mathrm{O}_{5}$ & $\mathrm{SO}_{3}$ & $\mathrm{Cl}$ & $\mathrm{K}_{2} \mathrm{O}$ & $\mathrm{CaO}$ & $\mathrm{TiO}_{2}$ & $\mathrm{~V}_{2} \mathrm{O}_{5}$ & $\mathrm{MnO}$ & $\mathrm{Fe}_{2} \mathrm{O}_{3}$ & $\mathrm{BaO}^{2}$ \\
8,92 & 21,7 & 16,6 & 0,4 & 0,23 & 0,06 & 0,84 & 4,33 & 4,49 & 0,04 & 0,57 & 27,1 & $n d$ \\
\hline $\mathrm{MgO}$ & $\mathrm{Co}_{3} \mathrm{O}_{4}$ & $\mathrm{ZnO}$ & $\mathrm{CuO}$ & $\mathrm{SrO}$ & $\mathrm{Y}_{2} \mathrm{O}_{3}$ & $\mathrm{ZrO}_{2}$ & $\mathrm{Nb}_{2} \mathrm{O}_{5}$ & $\mathrm{CeO}_{2}$ & $\mathrm{PbO}$ & $\mathrm{ThO}_{2}$ & $\mathrm{Ga}_{2} \mathrm{O}_{3}$ & $\mathrm{PF}$ \\
$\mathrm{nd}$ & 0,01 & 0,01 & $\mathrm{nd}$ & 0,02 & 0,01 & 0,67 & 0,17 & 0,34 & 0,02 & 0,02 & 0,01 & 13,4 \\
\hline
\end{tabular}

$\mathrm{nd}=$ não detectado, $\mathrm{PF}=$ perda ao fogo a $1050{ }^{\circ} \mathrm{C}$. 


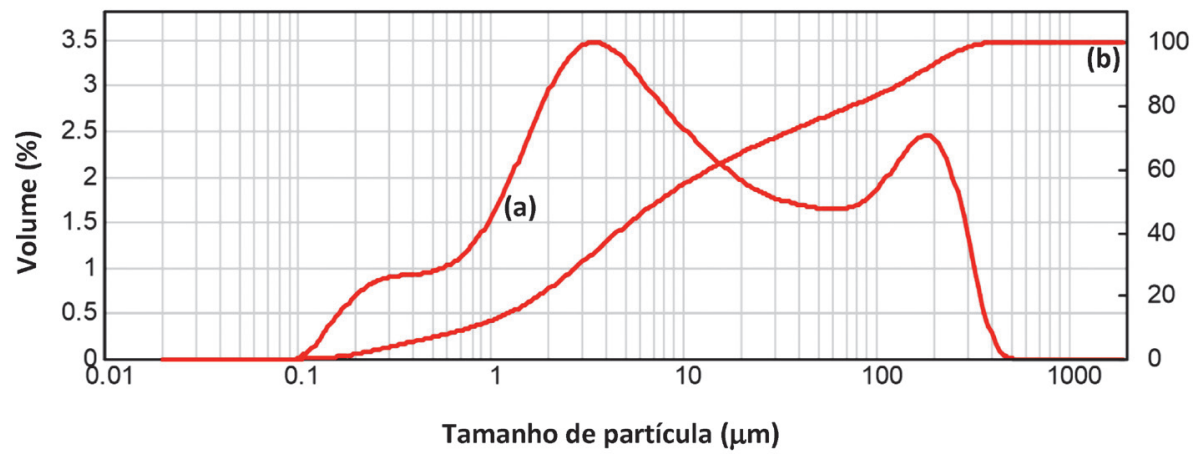

FIGURA 3 - Distribuição do tamanho das partículas na amostra de lama vermelha: (a) curva de frequência e (b) curva de distribuição cumulativa.

O valor de PCZ obtido para a amostra LM foi de 7,19. Esse valor está muito próximo daquele encontrado na lama vermelha estudada por TSAMO et al. (2014) e produzida a partir da bauxita da Cameroon Alumina LTD, que é de 7,09. No entanto, é superior ao valor de PCZ de amostras de lama vermelha de uma indústria de alumínio de Poços de Caldas, determinada por COSTA et al. (2009) $(\mathrm{PCZ}=5,95)$, e inferior àquele encontrado por APAK et al. (1998) em uma lama vermelha de uma indústria da Turquia $(\mathrm{PCZ}=8,3)$. O elevado valor de PCZ encontrado nas diversas amostras de lama vermelha indica que seus componentes também possuem essa característica. Por exemplo, o PCZ da hematita é igual a 9, o da goethita, 8,5 , e o do hidróxido de alumínio, em torno de 8,9 (ESSINGTON 2004).

$\mathrm{O}$ valor de CTC encontrado para LM foi baixo $\left(117,5 \mathrm{mmol}_{\mathrm{c}} \mathrm{kg}^{-1}\right)$, uma vez que os minerais que a compõem (quartzo, hematita, goethita) não apresentam carga permanente derivada de substituições isomórficas - como ocorre em alguns filossilicatos 2:1 (vermiculita e esmectitas) e zeólitas. Essa propriedade é, portanto, inerente à estrutura do mineral, que produz carga significativa para promover a troca iônica, independentemente do $\mathrm{pH}$ do meio
(FONTES et al. 2001). TSAMO et al. (2014) também determinaram a CTC de uma amostra de lama vermelha de Camarões e obtiveram valor de 174 mmolc kg-1.

Os testes de alcalinidade total realizados com a amostra LM revelaram, como esperado, valores elevados de bases à medida que se aumenta a relação lama vermelha:solução (Tabela 3).

Esses dados indicam que a lama vermelha é uma fonte potencial de radicais aniônicos $\left(\mathrm{OH}^{-}\right.$, $\mathrm{HCO}^{3-}$ e $\mathrm{CO}_{3}^{2-}$, que contribuem para tornar o meio alcalino (GRÄFE et al. 2009) e, consequentemente, neutralizar os ácidos. Para efeito de comparação, ressalta-se que os valores de alcalinidade das águas naturais, por exemplo, encontram-se na faixa de 20-200 $\mathrm{mg} \mathrm{L}^{-1}$.

\subsubsection{Latossolo Vermelho}

A análise dos dados de DRX obtidas por WU et al. (2013) para o solo analisado indica a presença de minerais de hematita $\left(\mathrm{Fe}_{2} \mathrm{O}_{3}\right)$, magnetita $\left(\mathrm{Fe}^{3+}{ }_{2} \mathrm{Fe}^{2+} \mathrm{O}_{4}\right)$, gibbsita $\left(\mathrm{Al}(\mathrm{OH})_{3}\right)$, quartzo $\left(\mathrm{SiO}_{2}\right)$ e ainda, caulinita $\left(\mathrm{Al}_{2} \mathrm{Si}_{2} \mathrm{O}_{5}(\mathrm{OH})_{4}\right)$ e anatásio $\left(\mathrm{TiO}_{2}\right)$.

TABELA 3 - Valores de alcalinidade total das soluções preparadas com lama vermelha.

\begin{tabular}{cc}
\hline Lama vermelha: água destilada & $\begin{array}{c}\text { Alcalinidade total } \\
\left(\mathrm{mg} \mathrm{L}^{-1}\right)\end{array}$ \\
\hline $1: 75$ & 1504,8 \\
$1: 150$ & 1003,2 \\
$1: 300$ & 752,4 \\
\hline
\end{tabular}


Ainda segundo os mesmos autores, a amostra de Latossolo Vermelho possui textura argilosa, $\mathrm{pH}$ moderadamente ácido $(5,4)$, composição química total com elevadas concentrações em $\mathrm{SiO}_{2}(31,3 \%)$, $\mathrm{Al}_{2} \mathrm{O}_{3}(22,6 \%)$ e $\mathrm{Fe}_{2} \mathrm{O}_{3}(27,4 \%)$ e, secundariamente de $\mathrm{TiO}_{2}(6,78 \%)$, refletindo a composição de seus principais minerais (Tabela 4).
Apesar do valor da CTC do solo $\left(58 \mathrm{mmol}_{\mathrm{c}}\right.$ $\mathrm{dm}^{-3}$ ) ter sido determinado em unidade de volume $\left(\mathrm{dm}^{-3}\right)$, verifica-se que é menor que a da lama vermelha $\left(117,5 \mathrm{mmol}_{\mathrm{c}} \mathrm{kg}^{-1}\right)$, reflexo dos minerais presentes no solo, bem como do baixo teor de matéria orgânica $\left(18 \mathrm{~g} \mathrm{dm}^{-3}\right)$. $\mathrm{O}$ valor do ponto de carga zero (PCZ) desse solo é de 4,6 (WU et al. 2013).

TABELA 4 - Características químicas de um Latossolo Vermelho na camada 0-20 cm: valores de $\mathrm{pH}$, matéria orgânica $(M O)$, acidez total $(H+A l)$, soma de bases $(S B)$, capacidade de troca catiônica $(C T C)$, saturação de bases $(V)$, potássio $(K)$, cálcio $(C a)$, magnésio $(M g)$, fósforo $(P)$, enxofre $(S)$, boro $(B)$, cobre $(C u)$, ferro $(F e)$, manganês $(M n)$ e zinco $(Z n)$. Fonte: WU et al. (2013).

\begin{tabular}{|c|c|c|c|c|c|c|c|c|c|c|c|c|c|c|c|}
\hline$p H$ & $\begin{array}{c}M O \\
\left(g d m^{-3}\right)\end{array}$ & $\mathrm{H}+$ & $\left(\mathrm{mmol}_{c} d m^{-3}\right)$ & $\begin{array}{l}\text { CTC } \\
\text { 3) }\end{array}$ & $\begin{array}{c}V \\
(\%) \\
\end{array}$ & & $\begin{array}{l}\mathrm{Ca} \\
\mathrm{ol}_{c} \mathrm{C}\end{array}$ & & $P$ & \multicolumn{5}{|c|}{$\left(m g d m^{-3}\right)$} & $Z n$ \\
\hline 5,4 & 18 & 20 & 37,7 & 58,0 & 65 & 2,9 & 29 & 6 & 5 & 3 & 0,2 & 6,1 & 11 & 23,7 & 0,4 \\
\hline
\end{tabular}

\subsection{Trabalhos experimentais}

\subsubsection{Incubação do solo}

De modo geral, a adição de $\mathrm{CaCO}_{3}$ e lama vermelha nas proporções estudadas $(0,5,1,3,5$, 10 e $20 \%$ ) no Latossolo Vermelho provocou um aumento significativo do $\mathrm{pH}$ do sistema (Tabela
5). Esse aumento é proporcional à quantidade de material adicionado, devido à presença de hidroxila e de carbonatos.

RIBEIRO \& GALBIATTI (2009) também verificaram que a aplicação de diferentes doses de lama vermelha (0 a $\left.140 \mathrm{t} \mathrm{ha}^{-1}\right)$ eleva o $\mathrm{pH}$ do solo, de 4,43 para 6,73 . COSTA et al. (2008), por sua vez, observaram que a adição de $2 \%$ em massa de

TABELA 5 - Ensaios de incubação do solo com lama vermelha (LM) e carbonato de cálcio (Cb) nas mesmas proporções, após 60 dias. Valores de $\mathrm{pH}$ em $\mathrm{KCl}, \mathrm{H}_{2} \mathrm{O}, \mathrm{CaCl}_{2}, \Delta \mathrm{pH}, \mathrm{PCZ}$ (ponto de carga zero) e AFAS (afastamento) dos sistemas com solo.

\begin{tabular}{c|cccccc}
\hline Solo $+\%$ & $p H \mathrm{KCl}$ & $\mathrm{pH} \mathrm{H}_{2} \mathrm{O}$ & $p \mathrm{HCaCl}$ & $\Delta p H$ & $P C Z^{*}$ & AFAS \\
\hline Solo & 6,20 & 7,25 & 5,05 & $-1,05$ & 4,15 & 3,10 \\
\hline $0,5 \% \mathrm{Cb}$ & 7,84 & 8,58 & 5,58 & $-0,74$ & 7,10 & 1,48 \\
$1 \% \mathrm{Cb}$ & 8,06 & 8,46 & 6,18 & $-0,40$ & 7,66 & 0,80 \\
$3 \% \mathrm{Cb}$ & 8,13 & 8,32 & 6,21 & $-0,19$ & 7,94 & 0,38 \\
$5 \% \mathrm{Cb}$ & 8,26 & 8,27 & 6,25 & $-0,01$ & 8,25 & 0,02 \\
$10 \% \mathrm{Cb}$ & 8,27 & 8,27 & 6,61 & 0 & 8,27 & 0 \\
$20 \% \mathrm{Cb}$ & 8,30 & 8,38 & 6,64 & $-0,08$ & 8,22 & 0,16 \\
\hline $0,5 \% \mathrm{LM}$ & 7,11 & 9,46 & 5,20 & $-2,35$ & 4,76 & 4,70 \\
$1 \% \mathrm{LM}$ & 7,20 & 9,04 & 5,71 & $-1,84$ & 5,36 & 3,68 \\
$3 \% \mathrm{LM}$ & 7,61 & 9,11 & 6,07 & $-1,50$ & 6,11 & 3,00 \\
$5 \% \mathrm{LM}$ & 7,89 & 9,34 & 6,25 & $-1,45$ & 6,44 & 2,90 \\
$10 \% \mathrm{LM}$ & 8,25 & 9,55 & 6,82 & $-1,30$ & 6,95 & 2,60 \\
$20 \% \mathrm{LM}$ & 8,56 & 9,66 & 7,35 & $-1,10$ & 7,46 & 2,20 \\
\hline
\end{tabular}

* Os dados de PCZ são teóricos e foram calculados com a equação (2). 
lama vermelha em amostras de Neossolo Quartzarênico e Latossolo Vermelho elevou os valores de pH a 8,5 e 7,9, respectivamente. Esses autores observaram, ainda, que a amostra de Neossolo possui menor poder tamponante que a de Latossolo, uma vez que essa última é argilosa e, consequentemente, consegue reter mais soluto devido à sua maior área superficial específica.

O valor teórico de PCZ do solo antes da incubação $(4,39)$ está muito próximo daquele obtido experimentalmente $(4,6) \mathrm{e}$, portanto, valida a equação proposta por UEHARA (1979), que calcula esse parâmetro de forma indireta. Em geral, observou-se que o PCZ do solo também aumenta com a adição, seja de $\mathrm{CaCO}_{3}$, ou de LM, acompanhando o aumento dos valores de $\mathrm{pH}$.

A tabela 5 mostra ainda que os valores de $\Delta \mathrm{pH}$ ficaram negativos após a incubação em todos os sistemas. Isso indica que as superfícies das partículas coloidais possuem uma predominância de cargas negativas e, portanto, promovem a atração de cátions do meio. Esse fato pode ser confirmado pelos valores de $\mathrm{pH}$ medidos em água, superiores aos de PCZ, que mostram o predomínio das cargas negativas no meio.

Em relação ao afastamento (AFAS), tanto o solo original quanto aqueles com lama vermelha, apresentaram valores mais elevados que os sistemas com $\mathrm{CaCO}_{3}$. No caso da LM, verifica-se que seus componentes elevam o $\mathrm{pH}_{\mathrm{H} 2 \mathrm{O}}$ muito mais que o $\mathrm{CaCO}_{3}$. Assim, considerando que a dispersão da argila aumenta quando o $\mathrm{pH}$ em água do solo for mais elevado que o PCZ, a erosão do solo pode se manifestar, uma vez que ocorre maior repulsão eletrostática e diminuição da floculação das partículas (RAIJ \& PEECH 1972).

No entanto, cabe ressaltar que os valores de AFAS diminuem com o aumento do teor de LM no sistema, uma vez que também ocorre aumento nos valores de PCZ.

3.2.2 Testes de batelada - retenção de $\mathrm{Pb}^{2+}$ em solução

Nos sistemas contendo apenas solo a eficiência de remoção de $\mathrm{Pb}^{2+}$ foi de $37 \%$. Com a adição de $\mathrm{CaCO}_{3}(>0,5 \%)$ e de lama vermelha (> 10\%), essa eficiência chegou a quase $100 \%$ - assim como na amostra contendo somente LM (Figura 4a). A quantidade de $\mathrm{Pb}^{2+}$ removida nesses sistemas foi de cerca de $4 \mathrm{mg}$ por grama de amostra (Figura 4b), demonstrando que o uso desses materiais melhora a capacidade de retenção de metais no solo.
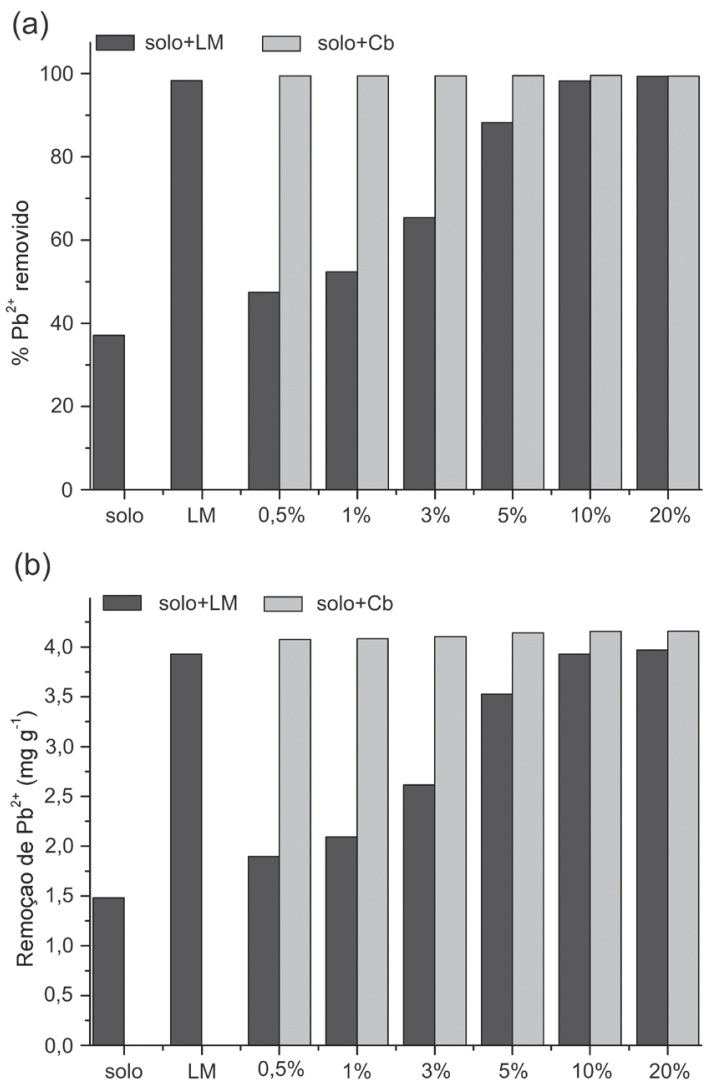

FIGURA 4 - (a) Eficiência (\%) e (b) quantidade de chumbo $(\mathrm{mg} / \mathrm{g})$ retida pelas amostras de solo, lama vermelha (LM) e das misturas de solo com diferentes

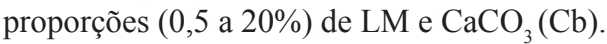

A adição de $\mathrm{CaCO}_{3}$ e LM no solo acabou elevando o $\mathrm{pH}$ das soluções de $\mathrm{Pb}^{2+}$ (Figura 5) e, nessas condições, todos os componentes apresentaram um balanço de carga líquida negativo, favorecendo a adsorção desse metal.

Considerando a presença de hidroxilas e carbonatos, que podem contribuir para a alcalinidade da lama vermelha, é possível que parte do $\mathrm{Pb}^{2+}$ tenha sido removida da solução por meio de precipitação (COSTA et al. 2009).

\subsubsection{Lixiviação ácida e extração sequencial}

Os dados de lixiviação ácida (com solução de ácido acético) das amostras saturadas com $\mathrm{Pb}^{2+}$ revelaram que esse metal se encontra fortemente retido nos materiais de estudo (Figura 6).

Os sistemas solos $+\mathrm{CaCO}_{3}$ foram os que mais conseguiram reter o metal durante a lixiviação ácida, chegando a liberar apenas $1 \%{\mathrm{de} \mathrm{Pb}^{2+}}^{2+}$ adsorvido em solos com $20 \%$ de $\mathrm{CaCO}_{3}$. Mesmo 


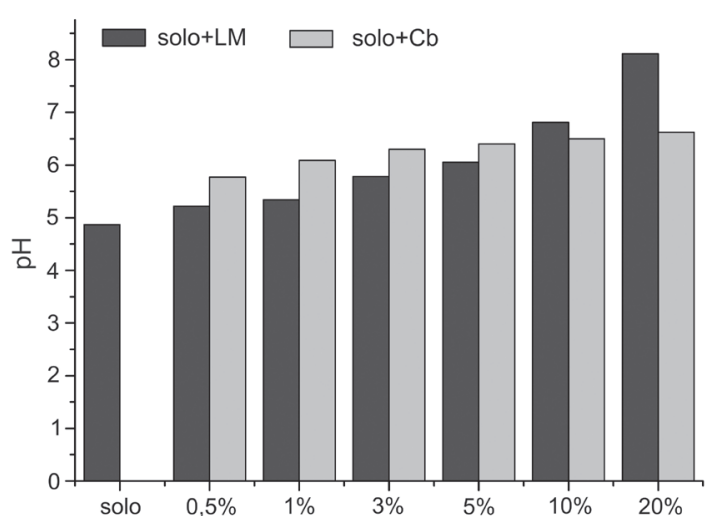

FIGURA 5 - Valores de pH das soluções de chumbo com solo e as misturas de solo e lama vermelha (LM) e $\mathrm{CaCO}_{3}(\mathrm{Cb})$ em diversas proporções.

em pequena quantidade $\left(1 \%\right.$ de $\left.\mathrm{CaCO}_{3}\right)$, a taxa de lixiviação de $\mathrm{Pb}^{2+}$ foi menor que a do solo (13\%).

Os sistemas solos + LM também liberaram $\mathrm{Pb}^{2+}$ em menor taxa $(<11 \%)$ que a do solo, chegando, por sua vez, a cerca de $3 \%$ em sistemas com $20 \%$ de LM (Figura 6 ).

COSTA et al. (2009) também notaram uma menor taxa de dessorção do $\mathrm{Pb}^{2+}$ da lama vermelha e chegaram a concluir que, provavelmente, grande parte desse metal tenha sido realmente adsorvida, pois caso tivesse sido precipitada, ela teria sido deslocada para a solução de dessorção.

Cabe ressaltar que, apesar da lama vermelha apresentar originalmente $0,02 \%$ de $\mathrm{Pb}^{2+}$, provavel-

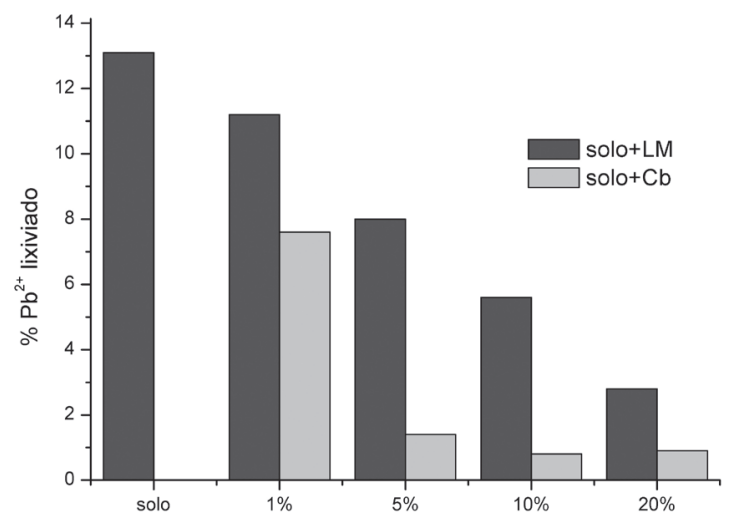

FIGURA 6 - Porcentagem de chumbo lixiviado com solução ácida (pH 4,9) de amostras de solo, solo com lama vermelha $(\mathrm{LM})$ e com $\mathrm{CaCO}_{3}(\mathrm{Cb})$ contaminadas com $\mathrm{Pb}^{2+}$.

mente essa parcela não foi solubilizada, uma vez que o teor desse íon na solução de lixiviação das amostras que receberam esse material permaneceu sempre abaixo da solução de lixiviação da amostra de solo (Figura 6).

Os resultados da extração sequencial permitiram observar que, de modo geral, o $\mathrm{Pb}^{2+}$ associou-se preferencialmente às fases menos móveis - como os óxidos cristalinos de $\mathrm{Al}$ nos sistemas com $\mathrm{CaCO}_{3} \mathrm{e}$ os óxidos amorfos de $\mathrm{Fe}$ e $\mathrm{Al}$ no caso da lama vermelha - e, depois, à fase residual (estrutura dos minerais) nos dois sistemas $\left(\mathrm{CaCO}_{3}\right.$ e $\left.\mathrm{LM}\right)$ (Figura 7). Uma pequena fração de $\mathrm{Pb}^{2+}$ encontra-se associada às fases trocável e de carbonatos da lama vermelha.

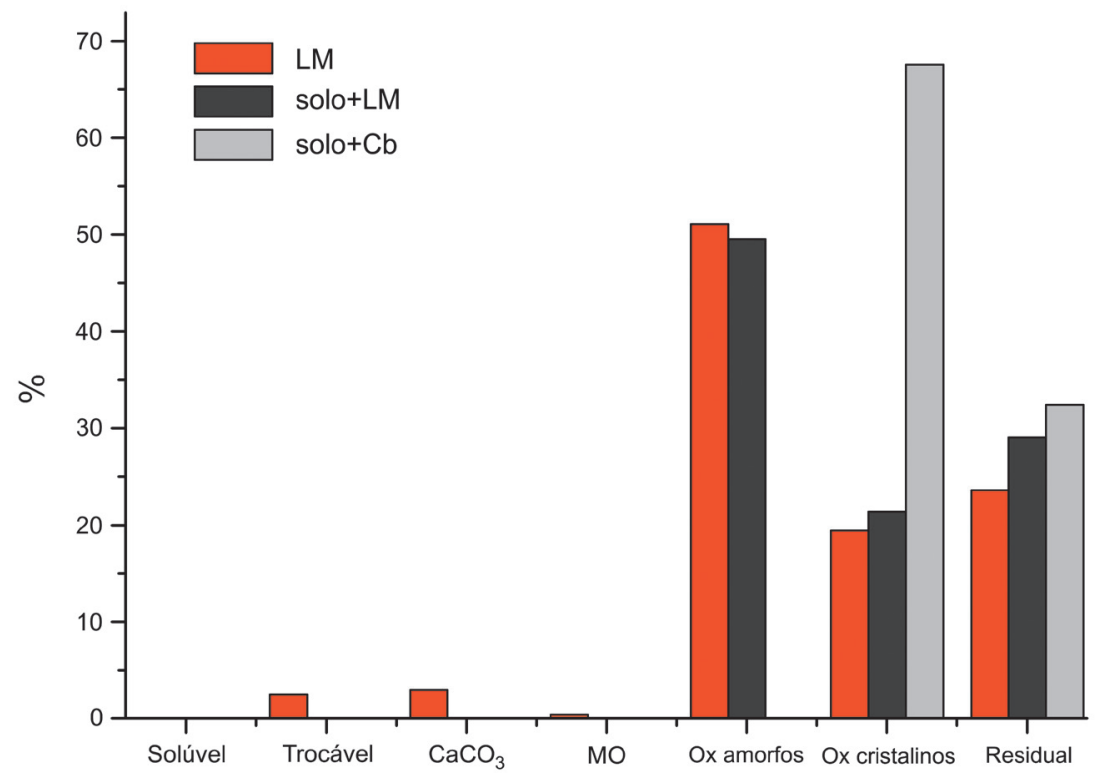

FIGURA 7 - Porcentagem de $\mathrm{Pb}^{2+}$ associada a cada fase da extração sequencial realizada nas amostras de solo $+\mathrm{CaCO}_{3}(\mathrm{Cb})$ e solo $+\mathrm{LM}$ e somente $\mathrm{LM}$, contaminadas com $\mathrm{Pb}^{2+}$. 
A maior parte do $\mathrm{Pb}^{2+}$ encontrada nos sistemas solos + LM associou-se aos óxidos de $\mathrm{Fe}$ e de Al pouco cristalinos (amorfos), seguido da fase residual e de óxidos cristalinos. A fase de óxidos amorfos não foi encontrada nos sistemas com $\mathrm{CaCO}_{3}$ e evidencia a exclusividade desses componentes na lama vermelha. Portanto, os principais constituintes da lama vermelha que promovem a retenção de $\mathrm{Pb}^{2+}$ são os óxidos amorfos de $\mathrm{Fe}^{3+} \mathrm{e}$ $\mathrm{Al}^{3+}$.

Nos solos com $\mathrm{CaCO}_{3}, \mathrm{o} \mathrm{Pb}^{2+}$ associou-se principalmente com os óxidos cristalinos de $\mathrm{Al}$ do solo, seguido da fase residual. Apesar de apresentar carbonato em sua composição, não foi observada sua associação com o $\mathrm{Pb}^{2+}$.

Segundo LU et al. (2011), durante a hidrólise e precipitação do $\mathrm{Fe}^{3+}$, o $\mathrm{Pb}^{2+}$ também pode ser co-precipitado e formar oxi-hidróxidos. Além disso, os óxidos de $\mathrm{Al}$ e $\mathrm{Fe}$ apresentam elevada superfície específica e cargas superficiais dependentes do $\mathrm{pH}$ do meio que, no caso, favorecem a adsorção de cátions, como o $\mathrm{Pb}^{2+}$. Vários autores constataram que

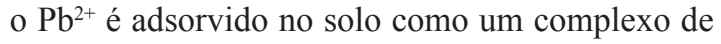
esfera interna (PIERANGELI et al. 2001, COSTA et al. 2009) tornando-o, portanto, pouco disponível no meio.

Esses dados revelam, portanto, que o $\mathrm{Pb}^{2+}$ pode encontrar-se associado aos componentes do solo e da lama vermelha (adsorvido, co-precipitado ou na forma de oxi-hidroxidos), inviabilizando a sua solubilidade, mesmo quando lixiviado com solução ácida, como comprovado no teste anterior.

\section{CONSIDERAÇÕES FINAIS}

O resíduo da indústria do alumínio (lama vermelha) é formado principalmente por óxidos e hidróxidos de ferro e de alumínio e possui um $\mathrm{pH}$ elevado (cerca de 10). A alcalinidade é dada principalmente por hidroxilas e carbonatos introduzidos durante o processo de produção de alumina.

O principal efeito da lama vermelha no solo é a elevação do $\mathrm{pH}$ e, consequentemente, do seu ponto de carga zero (PCZ). Esse aumento de $\mathrm{pH}_{\mathrm{H} 2 \mathrm{O}}$, em relação ao PCZ, indica o predomínio de cargas negativas na superfície das partículas do solo e, por isso, favorece a adsorção de cátions. Por outro lado, nessas condições, também poderá ocorrer o aumento dos valores de afastamento e, consequentemente, facilitar a dispersão das partículas do solo e, consequentemente, a erosão.

A adição de lama vermelha aumenta a quantidade de compostos, como óxidos e hidróxidos de ferro e de alumínio - minerais dependentes do $\mathrm{pH}$ e com cargas variáveis - que contribuem com o processo de adsorção de íons do meio.

Considerando que as características químicas e físicas da lama vermelha permitem alterar as propriedades eletroquímicas do solo, conclui-se que o uso desse material como corretivo de acidez, em relação aos carbonatos, pode não ser tão vantajoso, uma vez que os processos de dispersão das partículas do meio e de erosão poderão tornar-se mais acelerados.

Por outro lado, o uso controlado desse resíduo para a remoção de metais, como o $\mathrm{Pb}^{2+}$, mostrouse muito eficiente quando utilizado em proporções acima de 5\% do volume total do solo. Os óxidos amorfos de $\mathrm{Fe}$ e $\mathrm{Al}$ são os principais componentes diagnosticados na lama vermelha que retém o $\mathrm{Pb}^{2+}$ por adsorção, influenciados pelo $\mathrm{pH}$ do meio.

Devido ao grande volume de lama vermelha gerado pelas indústrias de alumínio e à falta de alternativas para o seu tratamento e disposição, esse resíduo poderá tornar-se um produto mais barato para o tratamento de solos e efluentes contaminados com metais pesados, se comparado com o carbonato e outros reagentes comumente empregados para promover a precipitação e adsorção desses contaminantes no meio.

\section{AGRADECIMENTOS}

Os autores agradecem à ALCAN (atual Novelis) pela cessão das amostras de lama vermelha. Ao CNPq pela bolsa de iniciação científica da aluna Vanessa Andrade. Aos relatores da Revista do Instituto Geológico, pelas sugestões e críticas que contribuíram para o aperfeiçoamento do artigo.

\section{REFERÊNCIAS BIBLIOGRÁFICAS}

ABNT - ASSOCIAÇÃO BRASILEIRA DE NORMAS TÉCNICAS. 2004. NBR 10.005. Lixiviação de resíduos. ABNT, 71 p.

ALBUQUERQUE, J.A.; BAYER, C.; ERNANI, P.R.; FONTANA, E.C. 2000. Propriedades físicas e eletroquímicas de um Latossolo Bruno afetadas pela calagem. Revista Brasileira de Ciência do Solo, 24: 295-300.

ALLEONI, L.R.F.; MELLO, J.W.V.; ROCHA, W.S.D. 2009. Eletroquímica, adsorção e troca iônica do solo. In: V.F. Melo \& L.R.F. Alleoni (eds) Química e Mineralogia do solo - parte II - Aplicações. SBCS, Viçosa, 685 p. 
ANTUNES, M.L.P.; CONCEIÇÃO, F.T.; NAVARRO, G.R.B. 2011. Caracterização da lama vermelha brasileira (resíduo do refino da bauxita) e avaliação de suas propriedades para futuras aplicações. In: International Workshop Advances in Cleaner Production, 3, São Paulo, Brazil, p.1-10.

APAK, R.; TÜTEM, E.; HÜGÜL, M.; HIZAL, J. 1998. Heavy metal cation retention by unconventional sorbents (red muds and fly ashes). Water Research, 32(2): 430-440.

ARANA, L.V. 2004. Princípios químicos de qualidade da água em aqüicultura. Editora da UFSC, Florianópolis, 231 p.

BENITES, V.M.; MENDONÇA, E.S. 1998. Propriedades eletroquímicas de um solo eletropositivo influenciadas pela adição de diferentes fontes de matéria orgânica. Revista Brasileira de Ciência do Solo, 22: 215-221.

BRUNORI, C.; CREMISINI, C.; MASSANISSO, P.; PINTO, V.; TORRICELLI, L. 2005. Reuse of a treated red mud bauxite waste: studies on environmental compatibility. Journal of Hazardous Materials, B117: 55-63.

CAMARGO, O.A.; MONIZ, A.C.; JORGE, J.A.; VALADARES, J.M.A.S. 2009. Métodos de análises química, mineralógica e física de solos do Instituto Agronômico de Campinas: Instituto Agronômico de Campinas (IAC), Campinas, 77 p. (Boletim Técnico, 106).

CAMPANHARO, M.; LIRA JUNIOR, M.A.; NASCIMENTO, C.W.A.; FREIRE, F.J.; COSTA, J.V.T. 2007. Avaliação de métodos de necessidade de calagem no Brasil. Caatinga, 20(1): 97-105.

CHVEDOV, D.; OSTAP, S.; LE, T. 2001. Surface properties of red mud particles from potentiometric titration. Colloids and surfaces A: Physicochemical and Engineering Aspects, 182: 131-141.

CICCU, R.; GHIANI, M.; SERCI, A.; FADDA, S.; PERETTI, R., ZUCCA, A. 2003. Heavy metal immobilization in the mining-contaminated soils using various industrial wastes. Minerals Engineering, 16: 187-192.

COSTA, E.T.S.; GUILHERME, L.R.G.; CURI, N.; OLIVEIRA, L.C.A.; VISIOLI, E.L.; LOPES,
G. 2008. Subproduto da indústria de alumínio como amenizante de solos contaminados com cádmio e chumbo. Revista Brasileira da Ciência do Solo, 32: 2533-2546.

COSTA, E.T.S.; GUILHERME, L.R.G.; CURI, N.; LOPES, G.; VISIOLI, E.L.; OLIVEIRA, L.C.A. 2009. Caracterização de subproduto da indústria de alumínio e seu uso na retenção de cádmio e chumbo em sistemas monoelementares. Química Nova, 32: 868-874.

DOYE, I.; DUCHESNE, J. 2003. Neutralization of acid mine drainage with alkaline industrial residues: laboratory investigation using batch-leaching tests. Applied Geochemistry, 18: 1197-1213.

DUCHESNE, J.; DOYE, I. 2005. Effectiveness of covers and liners made of red mud bauxite and/or cement kiln dust for limiting acid mine drainage. Journal of Environmental Engineering, 131(2): 1230-1235.

ESSINGTON, M.E. 2004. Soil and water chemistry: an integrative approach. CRC Press, Boca Raton, 553 p.

FONTES, M.P.F.; GJORUP, G.B.; ALVARENGA, R.C.; NASCIF, P.G.S. 1995. Calcium salts and mechanical stress effects on waterdispersible clay of oxisols. Soil Science Society of America Journal, 59(1): 224-227.

FONTES, M.P.F.; CAMARGO, O.A.; SPOSITO, G. 2001. Eletroquímica das partículas coloidais e sua relação com a mineralogia de solos altamente intemperizados. Scientia Agricola, 58(3): 627-646.

GOMES, P.C.; FONTES, M.P.F.; COSTA, L.M.; MENDONÇA, G.S. 1997. Extração fracionada de metais pesados em Latossolo Vermelho Amarelo. Revista Brasileira de Ciência do Solo, 21: 543-551.

GRÄFE, M.; POWER, G.; KLAUBER, C. 2009. Review of bauxite residue alkalinity and associated chemistry. CSIRO Document DMR-3610. May 2009. Project ATF0603: "Management of Bauxite Residues" Department of Resources, Energy and Tourism, Australian Government, $50 \mathrm{p}$.

GUPTA, V.K.; GUPTA, M.; SHARMA, S. 2001. Process development for the removal of lead 
and chromium from aqueous solutions using red mud - an aluminium industry waste. Water Research, 35(5): 1125-1134.

HESSE, P. R. 1971. A textbook of soil. Chemical Analysis. Chemical Publishing Co Inc., New York, $520 \mathrm{p}$.

HIND, A.R.; BHARGAVA, S.K.; GROCOT, S.C. 1999. The surface chemistry of Bayer process solids: a review. Colloids and Surfaces. A: Physicochemical and Engineering Aspects, 146: 359-374.

HO, G.; QIAO, L. 1998. Chromium speciation in municipal solid waste: effects of clay amendment and composting. Water Science Technology, 38(2): 17-23.

HYDRO. Como a alumina é extraída da bauxita. Disponível em http://www.hydro.com/pt/AHydro-no-Brasil/Sobre-o-aluminio/Ciclode-vida-do-aluminio/Refino-da-alumina/. Acessado em 4 março de 2015.

HYPOLITO, R.; ANDRADE, S.; SILVA, L.H.; NASCIMENTO, S.C. 2008. Alcalinidade metodologia para determinação em campo. Analytica, 6(35): 52-61.

KARA, M.; EMRULLAHOGLU, Ö.F. 2000. BCRfrom byproduct to brick: using red mud waste as a construction material. Ceramic Industry. Disponível em http:// www. ceramicindustry. com./ CDA/ Articleinformation/ features/ BNP_Features_Item/ 0,2710,8119,00. html. Acessado em 4 jul. 2002.

KER, J.C. 1997. Latossolos do Brasil. Geonomos, 5(1): 17-40.

KUMMER, L.; MELO, V.F.; BARROS, Y.J.; AZEVEDO, J.C.R. 2011. Extrações sequenciais de chumbo e zinco em solos de área de mineração e metalurgia de metais pesados. Revista Brasileira de Ciência do Solo, 35: 2005-2018.

LAAN, S.R. van der; VLIET, A. 1998. A concise analytical strategy applied to waste treatment technology. Journal of Geochemical Exploration, 62: 105-127.

LEMOS, R.C.; SANTOS, R.D. 1984. Manual de descrição e coleta de solo no campo. SBCS/ SNLCS, Campinas, $2^{\mathrm{a}}$ ed., 45 p.
LI,L.Y.;YETANG,H.;DUOJUN,W.; YONGXUAN, Z. 2010. Effect of red mud on the mobility of heavy metals in mining-contaminated soils. Chinese Journal of Geochemistry, 29: 191-196.

LOMBI, E.; ZHAO, F.; WIESHAMMER, G.; ZHANGA, G.; McGRATH, S.P. 2002. In situ fixation of metals in soils using bauxite residue: biological effects. Environmental Pollution, 118: 445-452.

LU, P.; NUHFER, N.T.; KELLY, S.; LI, Q.; KONISHI, H.; ELSWICK, E.; ZHU, C. 2011. Lead coprecipitation with iron oxyhydroxide nano-particles. Geochmica et Cosmochimica Acta, 75: 4547-4561.

MANN, S.S.; RITCHIE, G.S.P. 1993. The influence of $\mathrm{pH}$ on the forms of cadmium in four west australian soils. Australian Journal of Soil Research, 31: 255-270.

MEKARU, T.; UEHARA, G. 1972. Anion adsorption in ferruginous tropical soils. Soil Science Society America Proceedings, 36: 296-300.

MOTTA, A.C.V.; MELO, V.F. 2009. Química dos solos ácidos. In: V.F. Melo \& L.R.F. Alleoni (eds) Química e Mineralogia do solo - parte II - Aplicações. SBCS, Viçosa, 685 p.

OLPHEN, H. van. 1977. An introduction to clay colloid chemistry. New York, Jonh Wiley \& Sons, $318 \mathrm{p}$.

PIERANGELI, M.A.P.; GUILHERME，L.R.G.; OLIVEIRA, L.R.; CURI, N.; SILVA, M.L.N. 2001. Efeito da força iônica da solução de equilíbrio sobre a adsorção/dessorção de chumbo em Latossolos brasileiros. Pesquisa Agropecuária Brasileira, 36(8): 1077-1084.

PRADO, R.M.A. 2003. A calagem e as propriedades físicas de solos tropicais: revisão de literatura. Revista de Biociências, 9(3): 7-16.

RAIJ, B. van; PEECH, M. 1972. Eletrochemical properties of some oxisols and alfisols of the Tropics. Soil Science Society of America Journal, 36(4): 587-593.

RAIJ, B. van; ANDRADE, J.C., CANTARELLA, H., QUAGGIO, J.A. 2011. Análise Química para Avaliação da Fertilidade de Solos Tropicais. IAC, Campinas, 284 p. 
RIBEIRO, A.G.; CALBIATTI, J.A. 2009. Aplicação do resíduo da mineração de bauxita em canade-açúcar. Holos Environment, 8(1): 113-117.

SÁNCHEZ-MARTÍN, M.J.; GARCÍA-DELGADO, M.; LORENZO, L.F.; RODRÍGUEZ-CRUZ, M.S.; ARIENZO, M. 2007. Heavy metals in sew-age sludge amended soils determined by sequential extractions as a function of incubation time of soils. Geoderma, 142: 262-273.

SNARS, K.; GILKES, R.; HUGHES, J. 2002. Effect of bauxite residue (red mud) on the availability of phosphorus in very sandy soils. In: World Congress of Soil Science, 17, Thailand, p.1-8.

TESSIER, A.; CAMPBELL, P. G. C.; BISSON, M. 1979. Sequential extraction procedure for the speciation of particulate trace metals. Analytical Chemistry, 51(7): 844-851.

TSAMO, C.; PARFAIT, Z.A.; KAMGA, R.; BELIBI, B.P.D.; BIKIÉ-MBAH, J.B. 2014. Preparation and Characterization of Red mud derived from Minim-Martap (Cameroon) Bauxite. International Journal of Research in Chemistry and Environment, 4: 153-160.

UEHARA, G. 1979. Mineralo-chemical properties of oxisols. In: International Soil Classification
Workshop, 2, Malaysia, 1978. Bangkok, Soil Survey Division, Land Development Department, p.45-60.

USEPA - UNITED STATES ENVIRONMENTAL PROTECTION AGENCY. 1996. Method 3050, Acid digestion of sediments, sludges, and soils. Disponível em www.epa.gov/ epaoswer/hazwaste/test/pdfs/3050b.pdf. Revised on December, 1996. Acessado em 10 mai. 2015.

VARNAVAS, S.P.; BOUFOUNOS, D.; FAFOUTIS, D. 2005. An investigation of the potential application of bauxite residue in soil/sediment remediation. In: International Conference on Enviromental Science and Technology, 9, Rhodes Island, Greece, Proceedings, A-15721577.

WORLD ALUMINUM ORG. 2003. Bauxite residue. Disponível em http://www.worldaluminium.org/environment/challenges/ residue.html. Acessado em 17 jun. 2003.

WU, L.F.; SHINZATO, M.C.; ANDRADE, S.; FRANCHI, J.G.; ANDRADE, V.S. 2013. Efeito da adição de zeólita e vermiculita na lixiviação de potássio do solo. Revista do Instituto Geológico, 34(1): 57-67.

\section{Endereço dos autores:}

Mirian Chieko Shinzato, Vanessa da Silva Andrade, Marília Mayumi Augusto dos Santos e Vinícius Tadeu Ribeiro - Instituto de Ciências Ambientais, Química e Farmacêutica da Universidade Federal de São Paulo, Rua São Nicolau, 210, CEP:09913-030, Diadema, SP. E-mail: mirianshinzato@gmail.com, v.andrade23@gmail.com,mayumimarilia@gmail.com, biu.vinicius@gmail.com

José Vinícius Martins e Flávio Machado de Souza Carvalho - Instituto de Geociências, Universidade de São Paulo, Rua do Lago, 562, CEP: 05508-080, São Paulo, SP. E-mail: viniciusmartins@usp.br, flavioms@usp.br

Artigo submetido em 18 de setembro de 2015, aceito em 25 de novembro de 2015. 